\title{
Investigation on the Possibility of Using Available Sunshine Duration Data of a Relatively Close Region to Estimate Global Solar Radiation for a Different Region
}

\author{
Adeola S.O ${ }^{1}$ and Adeniji N.O \\ ${ }^{1-2}$ Department of Physics And Solar Energy \\ Bowen University, Iwo, Osun State, \\ Nigeria
}

\begin{abstract}
Estimation of global solar radiation using existing models becomes necessary in areas where measurements are not carried out due to lack of technical knowledge, unavailability of measuring instrument and cost of getting such measurements if available.

In this study, the possibility of estimating the global solar radiation for a particular location using another location's sunshine duration data is explored due to the closeness in the latitude of the two locations and to what extent is the estimation true. Ibadan's (latitude 7.37750N) sunshine duration data is used as Iwo's (latitude 7.62920N) sunshine duration data and employed in the Angstrom - Prescott's sunshine based model, while retaining the latitude of Iwo in the model, mean sunset/rise hour angle and extraterrestrial radiation. The sunshine duration data for Ibadan (2008 - 2012) was gotten from International Institute of Tropical Agriculture, Ibadan while the measured global solar radiation data for Iwo (2014 - 2015) was measured at Bowen University Iwo, Osun state in Nigeria.
\end{abstract}

The estimated global solar radiation for Iwo is validated with measured global solar radiation at Iwo by carrying out some statistical analysis like mean bias error (-0.03), root mean square error (0.81), mean percentage error (-0.23), Nash-Sutcliffe error ( $r 2)$ or coefficient of determination (0.88), coefficient of correlation (0.94). The estimated values when validated against the measured values performed excellently well. Hence it is possible to use the available sunshine duration data of another location as the sunshine duration data when estimating the global solar radiation available at the location of interest.

Keywords: Global solar radiation, Sunshine duration, Clearness index, Extraterrestrial radiation.

\section{INTRODUCTION}

Global solar radiation is the sum of both beam solar radiation and diffused solar radiation. Solar radiation is the energy coming from the sun in form of radiant energy to the earth's surface. The importance of solar radiation is so vital such that without solar radiation, life on earth will be very difficult for any living thing to survive. Harnessing this radiant energy from the sun has become necessary if life on earth must be sustained, because other forms of energy that are used in industries, have negative impact on human health. Furthermore, the applications of some energy source such as coal in the industry has led to high emission of carbon dioxide (CO2) which is a greenhouse gas and contributes to global warming.

Since the trend of energy application has shifted to solar energy, the knowledge of the amount of solar radiation at the location where solar energy is to be harnessed is very important. The amount of global solar radiation is measured by using an instrument called pyrheliometer. The knowledge of the amount of solar radiation is not only useful for solar energy applications, it is also useful for architectural designs, development of crop growth models and to carry out designs of irrigation systems.

Estimation of global solar radiation using existing models becomes necessary in areas where measurements are not been carried out due to lack of technical knowledge, unavailability of measuring instrument and cost of getting such measurements if available. Usually the models that will be used to estimate the global solar radiation employ different parameters that are available 
measured inputs such as temperature, sunshine duration, cloud cover, precipitation, relative humidity and other meteorological parameters.

\section{MATERIALS AND METHODS}

\subsection{STUDY AREAS}

The geographical distance between Iwo and Ibadan is 42 kilometers.

\subsubsection{IWO}

Iwo town, Osun state, southwestern Nigeria lies 6 miles $(10 \mathrm{~km})$ north of the Iwo railway station on the Lagos-Kano railway and at the intersection of roads from Ibadan, Oyo, and Ogbomosho, on a low hill at the edge of a savanna and forest vegetation, latitude $7.6292^{\circ} \mathrm{N}$ and longitude $4.1872^{\circ} \mathrm{E}[1]$.

\subsubsection{IBADAN}

Ibadan was founded in the 1820's and lies between latitude $7^{\circ} 02^{\prime} 49^{\prime \prime}$ and $7^{\circ} 43^{\prime} 21^{\prime \prime} N$ longitude $3^{\circ} 31^{\prime} 58^{\prime \prime}$ and $4^{\circ} 08^{\prime} 20^{\prime \prime} E$. Ibadan is the capital of Oyo state, Nigeria.

\subsection{DATA OBTAINED}

Mean sunshine duration data for five years (2008-2012), January till December was gotten from International Institute of Tropical Agriculture, Ibadan, Oyo State. Global solar radiation data for one year (2014-2015) for Iwo was obtained from Bowen University Iwo, Osun State.

\subsection{DATA ANALYSIS}

In this study, Angstrom Prescott's model is used to estimate monthly mean values of global solar radiation. MatLab tool was used for the data analysis and Microsoft Excel.

The model used sunshine duration to estimate daily mean values of solar radiation on a horizontal surface.

Table 1: Sunshine based model used in the study

\begin{tabular}{|c|c|c|}
\hline Model no & Regression & Source \\
\hline 1 & $\frac{H}{H_{0}}=a+b\left(\frac{S}{S_{0}}\right)$ & Angstrom-Prescott (1940) \\
\hline
\end{tabular}

$H$ is daily mean values of global radiation ( $\mathrm{MJ} / \mathrm{m}^{2}$ day), $\mathrm{S}_{0}$ is the daily average value of day length, $\mathrm{S}$ is the number of bright sunshine hour and 'a' and 'b' values are known as Angstrom constants and they are empirical. $H_{0}$ is daily mean values of extraterrestrial radiation (MJ/m² day), calculated using Eq. (1) as described by ([2], [3]; [4]):

$H_{0}=\left(\frac{24 \times 3600}{\pi}\right) I_{S C} E_{0}\left[\cos (\varphi) \cos (\delta) \sin \left(\omega_{s}\right)+\frac{\pi \omega_{s}}{180} \sin (\varphi) \sin (\delta)\right]$

$I_{S C}=\frac{1367 \times 3600}{1000000}$ MJm $^{-2}$ ourr $^{-1}=1.367$ MJm $^{-2}$ hour $^{-1}$

is the solar constant,

$E_{0}$ represents the eccentricity correction, and described using Eq. (3) in Eq. (1)

$E_{0}=1+0.033 \cos \left(\frac{360 n_{d}}{365}\right)$

$n_{d}$ is the day number of the year /Julian day ( $1 \mathrm{Jan}, n_{d}=1$ and 31st December, $n_{d}=365$ ), $\varphi$ is the latitude of the site, $\delta$ the solar declination and, $\omega_{s}$, the mean sunset hour angle for the given month. The solar declination $(\delta)$ and the mean sunset hour angle $\left(\omega_{s}\right)$ can be calculated as suggested by [5]:

$\delta=23.45 \sin \left[360\left(\frac{284+n_{d}}{365}\right)\right]$

And

$\omega_{s}=\cos ^{-1}(-\tan \varphi \tan \delta)$

For a given day, the maximum possible sunshine duration (monthly values of day length, ( $S_{0}$ ) can be computed by using [5]: 
$S_{0}=\frac{2}{15} \omega_{s}$

The constants $\mathrm{a}$ and $\mathrm{b}$ in table 1 are regression coefficients given as:

$a=-0.110+0.235 \cos (\varphi)+0.323\left(\frac{S}{S_{0}}\right)$.

$b=1.449-0.553 \cos (\varphi)-0.694\left(\frac{S}{S_{0}}\right)$

To compute estimated values of daily mean global solar radiation $(H)$, the values of a and $\mathrm{b}$ computed from equations 7 and 8 were used for the model in Table 1 .

The daily mean value of global solar radiation $(H)$ was normalized by dividing with daily mean values of extraterrestrial radiation $\left(H_{0}\right)$. Clearness index $\left(K_{t}\right)$ can be defined as the ratio of the values of the monthly mean global radiation $H$, to the calculated/predicted horizontal/extraterrestrial solar radiation $\left(H_{0}\right)[6]$.

$K_{t}=\frac{H}{H_{0}}$

In this study, the value used for $\mathrm{a}$ and $\mathrm{b}$ are 0.114 and 0.517 respectively.

\section{RESULTS AND DISCUSSION}

Table 2: Measured $\left(\mathrm{H}_{\mathrm{m}}\right)$ and Estimated Global Solar Radiation $\left(\mathrm{H}_{\mathrm{e}}\right)$ for Iwo, Extraterrestrial radiation $\left(\mathrm{H}_{0}\right)$, Clearness index $\left(\mathbf{K}_{t}\right)$, Sunshine hour $(\mathbf{S})$, Relative Sunshine Hour $\left(\mathbf{S} / \mathbf{S}_{\mathbf{0}}\right)$ for Iwo

\begin{tabular}{|l|l|l|l|l|l|l|}
\hline \multicolumn{1}{|c|}{ Month } & $\mathbf{H}_{\mathbf{m}}\left(\mathbf{M J} / \mathbf{m}^{2}\right)$ & $\mathbf{H}_{\mathbf{e}}\left(\mathbf{M J} / \mathbf{m}^{2}\right)$ & $\mathbf{H}_{\mathbf{0}}\left(\mathbf{M J} / \mathbf{m}^{2}\right)$ & $\mathbf{K}_{\mathbf{t}}$ & $\mathbf{S}(\mathbf{h r})$ & $\mathbf{S} / \mathbf{S}_{\mathbf{0}}$ \\
\hline January & 13.93 & 14.19 & 33.06 & 0.43 & 7.07 & 0.61 \\
\hline February & 15.24 & 14.76 & 35.23 & 0.42 & 6.86 & 0.58 \\
\hline March & 15.58 & 14.23 & 37.17 & 0.38 & 6.19 & 0.52 \\
\hline April & 16.18 & 15.01 & 37.68 & 0.39 & 6.66 & 0.55 \\
\hline May & 13.92 & 14.52 & 36.93 & 0.39 & 6.69 & 0.54 \\
\hline June & 12.39 & 14.05 & 36.22 & 0.39 & 6.65 & 0.54 \\
\hline July & 10.55 & 10.75 & 36.43 & 0.29 & 4.37 & 0.35 \\
\hline August & 8.25 & 8.65 & 37.15 & 0.23 & 2.83 & 0.23 \\
\hline September & 10.50 & 9.98 & 37.10 & 0.27 & 3.61 & 0.29 \\
\hline October & 13.35 & 13.07 & 35.58 & 0.37 & 5.69 & 0.48 \\
\hline November & 14.34 & 15.02 & 33.39 & 0.45 & 7.54 & 0.65 \\
\hline December & 15.22 & 14.83 & 32.22 & 0.46 & 7.76 & 0.67 \\
\hline
\end{tabular}


International Journal of Advances in Scientific Research and Engineering (ijasre), Vol 5 (2), February-2019

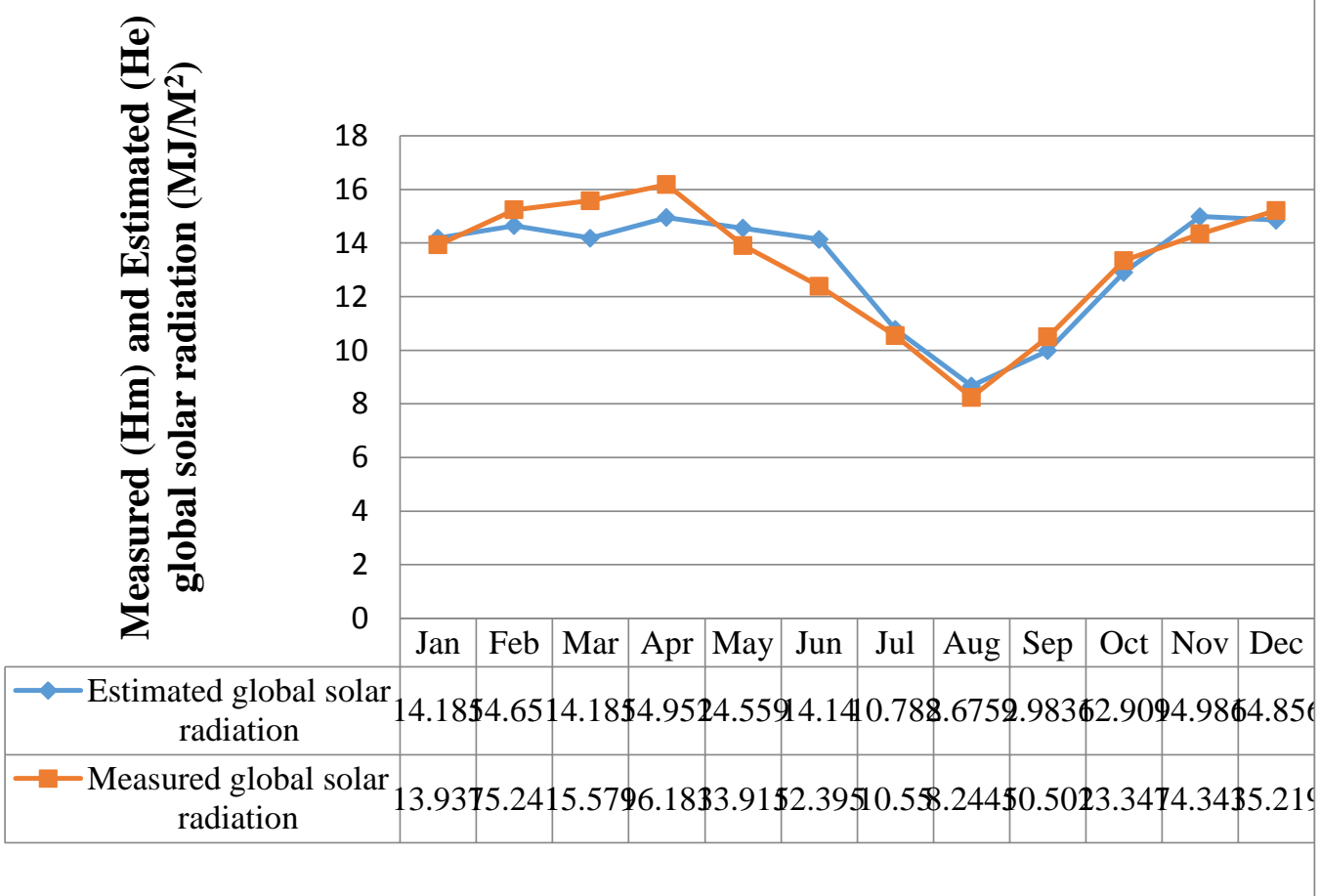

Figure 1: Monthly Variation of Measured and Estimated Global Solar Radiation for Iwo (MJ/m²)

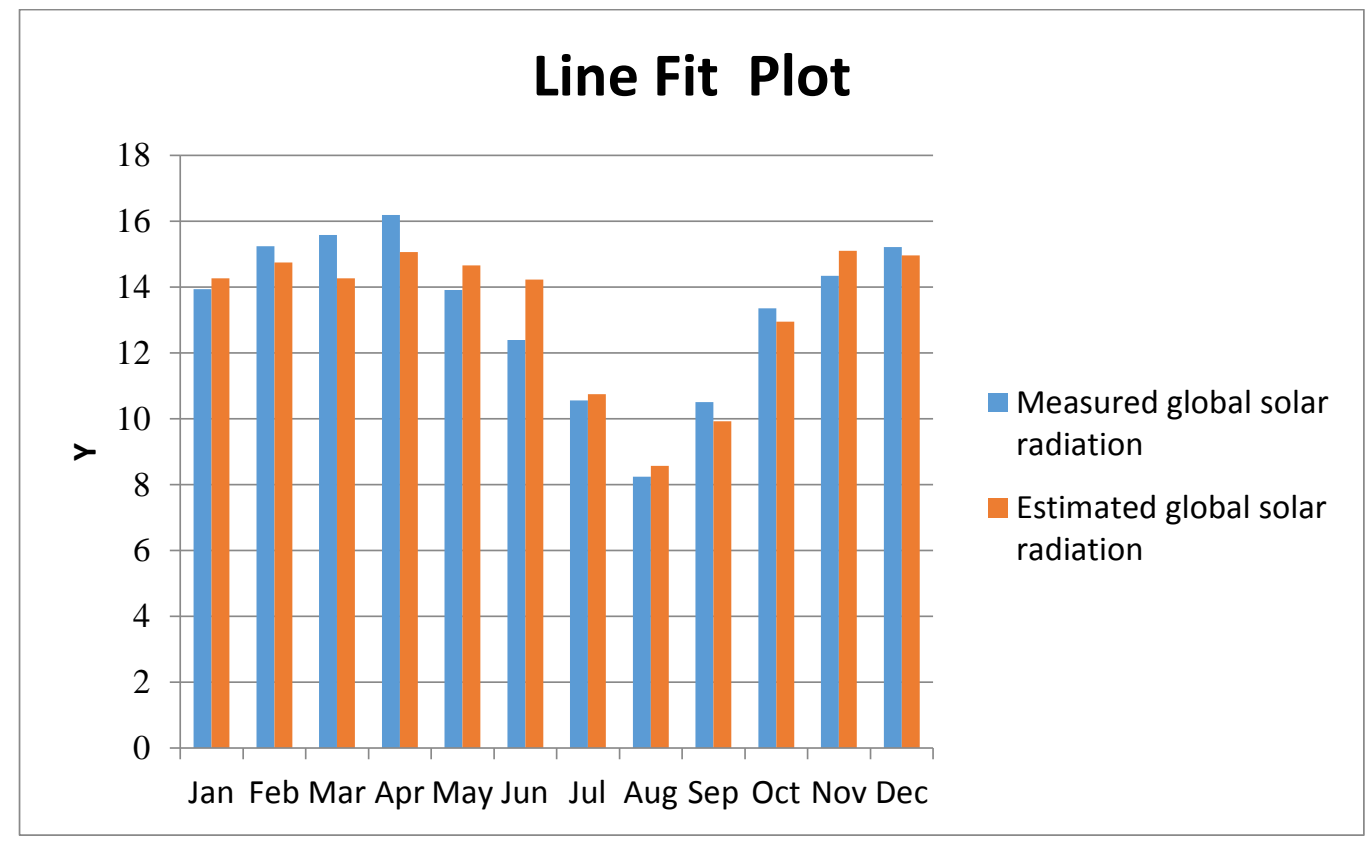

Figure 2: Line fit plot between Measured and Estimated global solar radiation for Iwo 
International Journal of Advances in Scientific Research and Engineering (ijasre), Vol 5 (2), February-2019

\subsection{STATISTICAL TESTS}

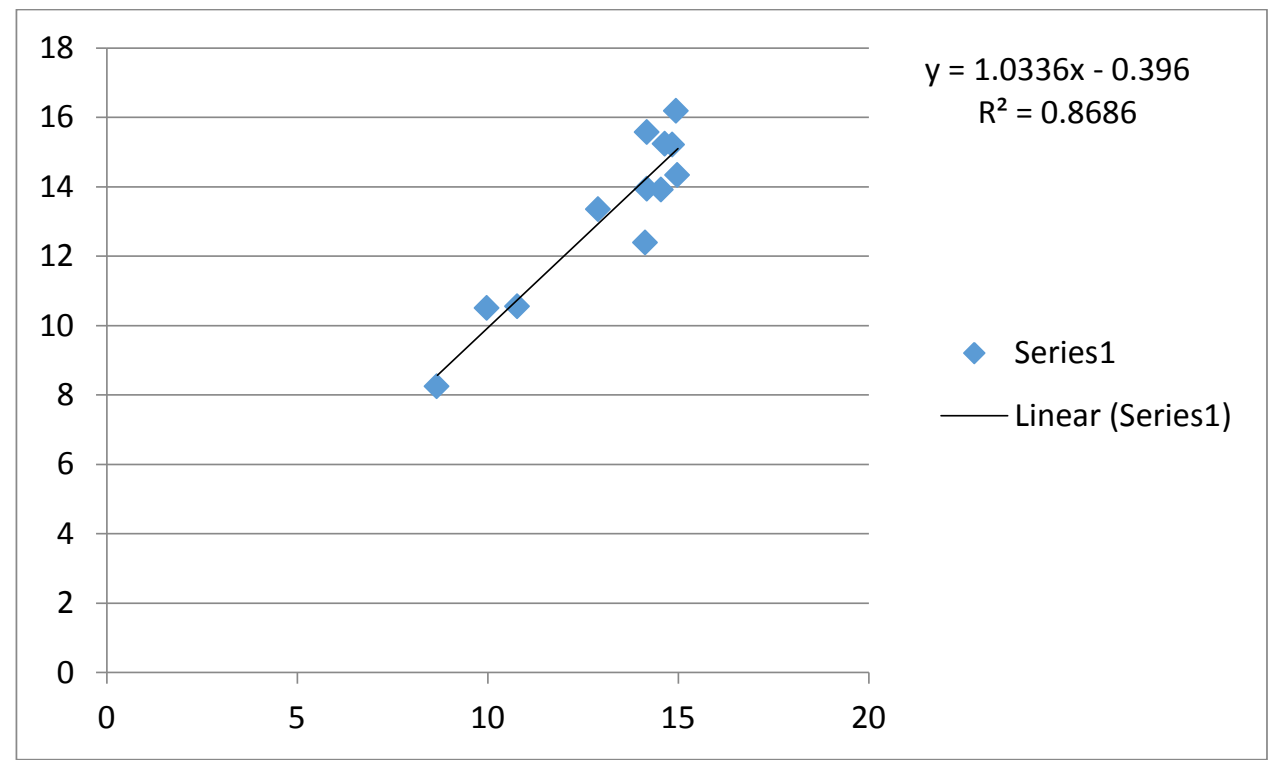

Figure 3: Variation of Measured Global Solar Radiation with respect to Estimated Global Solar Radiation

Table 3: Mean Bias Error(MBE), Root-Mean Square Error(RMSE), Mean Percentage Error(MPE), Coefficient of Determination $\left(\mathbf{R}^{2}\right)$, Coefficient of Correlation $(\mathbf{R})$

\begin{tabular}{|l|l|l|l|l|}
\hline MBE & RMSE & MPE & $\mathbf{R}^{2}$ & $\mathbf{R}$ \\
\hline-0.05 & 0.85 & -0.37 & 0.87 & 0.93 \\
\hline
\end{tabular}

\subsubsection{Mean Bias Error}

$$
M B E=\frac{1}{n} \sum_{1}^{n}\left(H_{i, \text { calc }}-H_{i, \text { meas }}\right)
$$

This test helps to calculate the error or the deviation of the calculated value from the measured value and provides information on long-term performance. A low MBE value is desired. A negative value gives the average amount of underestimation in the calculated value. The value -0.05 show that there is a little underestimation and a little deviation of the estimated global solar radiation from the measured global solar radiation.

\subsubsection{Root Mean Square Error}

$$
R M S E=\left[\frac{1}{n} \sum_{1}^{n}\left(H_{i, \text { calc }}-H_{i, \text { meas }}\right)^{2}\right]^{1 / 2}
$$

The value of RMSE should always be positive, ideally it should be zero. The smaller the value, the better the model's performance [7].

The value 0.85 shows the closeness of the estimated global solar radiation to zero which is the ideal case.

\subsubsection{Mean Percentage Error (MPE)}

$$
\operatorname{MPE}(\%)=\frac{1}{n} \sum_{1}^{n}\left(\frac{\left(H_{i, \text { calc }}-H_{i, \text { meas }}\right)}{H_{i, \text { meas }}}\right) * 100
$$

The mean percentage error is the average or mean of all the percentage errors. A percentage error between $-10 \%$ and $+10 \%$ is considered acceptable[8].

The value $-0.37 \%$ is considered highly acceptable. 


\subsubsection{COEFFICIENT OF DETERMINATION $\left(\mathbf{R}^{2}\right)$}

$$
N S E=1-\frac{\sum_{1}^{n}\left(H_{i, \text { calc }}-H_{i, \text { meas }}\right)^{2}}{\sum_{1}^{n}\left(\bar{H}_{\text {meas }}-H_{i, \text { meas }}\right)^{2}}
$$

A model is more efficient when NSE is closer to 1[9].

The value 0.87 approximately 0.9 is very close to 1 , hence considered an excellent performance.

\subsubsection{COEFFICIENT OF CORRELATION (R)}

This parameter measures the strength and the direction of a linear relationship between the measured and estimated values. The value of $\mathrm{R}$ is between -1 and +1 . The + and - signs are used for positive linear correlations and negative linear correlations, respectively. If there is no linear correlation or a weak linear correlation, $\mathrm{R}$ is close to 0 . A value near zero means that there is a random, nonlinear relationship between the two variables but it should approach to 1 as closely as possible for better modeling. The value 0.93 show a negative linear correlation and it is also close to 1 hence considered an excellent performance.

\section{CONCLUSION}

The results of the statistical test carried out showed little error between the estimated and measured global solar radiation at the location of interest (Iwo).

The result of this study shows that the available sunshine duration data for another location can be used as an estimate or approximate measurement for the location of Interest that has no availability of sunshine duration data due to lack of measuring instruments.

\section{ACKNOWLEDGMENT}

I wish to thank Prof. Theophilus Aro (Professor of Atmospheric Physics, Bowen University Iwo, Nigeria), Dr. Jacob Akinpelu (PhD Atmospheric Physics, Bowen University and Mr Nathaniel Adeniji (Msc Physics, Bowen University) for their words of encouragement during the period of this study, and review of the initial draft of this study. I also thank the International Institute of Tropical Agriculture, Ibadan and Bowen University, Iwo for making available to me the data used for this study.

\section{REFERENCES}

1. Iwo - Nigeria. (2009). In Encyclopædia Britannica online. Retrieved from https://www.britannica.com/place/Iwo-Nigeria

2. Prescott J.A., (1940). Evaporation from a water surface in relation to solar radiation. Trans. R. Soc of Australia ,64, 114-125.

3. Torgul I., 2009: "Estimation of Solar Radiation from Angstroms Coefficients by Using Geographical and Meteorological Data in Bishkek, Kyrgyzstan. ”Journal of Thermal Science and technology. 29 (2): 99-108.

4. Medugu D.W. and Yakubu D., (2011). Estimation of Mean Monthly Global Solar Radiation in Yola (Nigeria) using Angstrom Model. Advances in Applied Science Research, 2 (2): 414-421.

5. Duffie, J.A. and Beckman, W.A., (1991). Solar Engineering of Thermal Processes, 3rd edition. John Wiley and Sons, New York.

6. Falayi E.O., Rabiu A.B. and Teliat R.O., (2011). Correlations to Estimate Monthly mean of daily diffuse solar radiation in some selected cities in Nigeria. Advances in Applied Science Research 2(4): 480-490.

7. Namrata, K., Sharma, S.P. and Saksena, S.B.L., (2012). Comparison of Estimated Daily Global Solar Radiation Using Different Empirical Models. International Journal of Science and Advanced Technology (ISSN 2221-8386), Vol. 2 , No 4.

8. Muzathik, A.M., Nik, W.B.W., Ibrahim, M.Z., K.B. Samo, K. Sopian and Alghoul M.A., (2011). Daily global solar radiation estimate based on sunshine hours. International Journal of Mechanical and Materials Engineering (IJMME), Vol.6, No.1, 75-80.

9. Chen R., Ersi K., Yang, J. Lu S. and Zhao W., (2004). Validation of five global radiation models with measured daily data in China. Energy Conversion and Management, 45, 1759-1769. 